\title{
Nonassociative habituation, US preexposure, and backward inhibitory conditioning with signaled and unsignaled USs
}

\author{
DOUGLAS A. WILLIAMS and J. BRUCE OVERMIER \\ University of Minnesota, Minneapolis, Minnesota
}

\begin{abstract}
In a conditioned suppression experiment, rats received a single, massed session of conditioning in which one backward conditioned inhibitory stimulus (CS-) followed shocks that were signaled by a visual cue, and a second backward CS- followed shocks that were unsignaled. Conditioning was preceded by a preexposure phase in which some groups of rats were preexposed to unsignaled shock, while others were not preexposed and remained in the experimental apparatus in the absence of shock. The groups were further distinguished by whether US preexposure and conditioning occurred in the same or different contexts, and by whether conditioning began immediately or after a 24-h rest period in the home cage. Although the conditioning itself was effective in establishing the visual cue as a conditioned excitor in the nonpreexposed groups, it was not effective in establishing the two backward cues as reliable inhibitors with either signaled or unsignaled USs. After 210 US preexposures, however, the same conditioning sessions did yield conditioned inhibition to both CS-s. A 24-h rest period in the home cage reduced the magnitude of, but did not completely abolish, the facilitative effect of US preexposure on inhibitory conditioning. Other tests demonstrated that US preexposure had retarded excitatory conditioning to the visual cue. This interference with excitatory conditioning was unchanged in magnitude after the 24-h rest period. The facilitative effect of US preexposure on backward inhibitory conditioning, and the interference effect on excitatory conditioning, were both eliminated by a change in context between US preexposure and conditioning. These observations encourage predominantly associative accounts of the effects, but allow for a small nonassociative habituation component.
\end{abstract}

Animals faced with identical relationships between a conditioned stimulus (CS) and an unconditioned stimulus (US) may respond quite differently depending on their previous experience with the US. The present experiment focuses on the mechanisms that underlie the retarded emergence of excitatory conditioning (e.g., MacDonald, 1946; Mis \& Moore, 1973) and the facilitation of inhibitory conditioning (e.g., Hinson, 1982; Overmier, Payne, Brackbill, Linder, \& Lawry, 1979; Saladin \& Tait, 1986) that reliably follow US preexposure. Two classes of theoretical mechanisms that have been brought to bear on these complementary effects of US preexposure include nonassociative habituation and associative accounts (see LoLordo \& Randich, 1981; Randich \& LoLordo, 1979a, 1979b). Nonassociative habituation accounts (e.g., MacDonald, 1946; Solomon \& Corbit, 1974) interpret the effects of US preexposure in terms of changes in the subject's responsiveness over successive US presentations. Associative accounts (e.g., Gibbon \& Balsam, 1981; Rescorla \& Wagner, 1972), on the other hand, claim that

\footnotetext{
This research was supported by grants to J. B. Overmier and the Center for Research in Learning, Perception and Cognition. We thank Anastasia Droungas, Kelly Stanhope, and Andy Delamater for comments on an earlier version of this paper. Requests for reprints may be sent to Doug Williams, Psychology Department, Dalhousie University, Halifax, Nova Scotia B3H 4J1, Canada.
}

animals learn that USs occur in particular contexts, and that this contextual learning modulates later learning/ performance to discrete CSs.

Nonassociative habituation accounts were initially developed in an effort to describe the mechanisms underlying the phenomenon of short-term habituation-a decline in the probability and/or vigor of a response that may result after a series of closely spaced US presentations (Harris, 1943; Jennings, 1906; Prosser \& Hunter, 1936; Thompson \& Spencer, 1966). More recently, nonassociative habituation accounts have been extended in an attempt to explain the effects of US preexposure on later Pavlovian conditioning. Such accounts are based upon either passive or active mechanisms. According to a passive mechanism, the animal's responsiveness to the US simply wanes as a result of experience, rather than being actively inhibited by some other process. Some examples of a passive model include adaptational accounts (Kamin, 1961; MacDonald, 1946; Taylor, 1956), which suggest that the animal perceives the US as being less intense after US preexposure. The observation that US preexposure retards excitatory conditioning is easily interpreted in terms of a reduction in the perceived magnitude of the US. In recent years, however, passive accounts have lost popularity in the conditioning literature because they fail to account for the facilitative effect of US preexposure on inhibitory conditioning. A preexposed US that is perceived 
as being less intense should have a reduced capacity to act as a reinforcer for both excitatory and inhibitory conditioning.

Nonassociative habituation models based upon active mechanisms (e.g., Denny, 1971; Solomon \& Corbit, 1974; Wendt, 1931) have not encountered the same difficulties as have passive models. These models invoke a secondary process, which is strengthened by repeated US presentations, and which actively suppresses the animal's primary reaction to the US. For example, Solomon and Corbit (1974) have offered an opponent-process interpretation of the reduced affective impact of a US over trials. Their model assumes that the onset of a motivationally significant US elicits a primary affective process called the $a$ process. The $a$ process is unchanging over trials and is maximally effective on the first presentation of the US. This primary $a$ process is opposed by a secondary process, the $b$ process, which has properties antagonistic to the $a$ process. On the first few US presentations, the $b$ process is thought to be sluggish in its evocation and much weaker in strength than the $a$ process. With repeated, massed presentations of the US, the $b$ process grows rapidly, in terms of both speed of recruitment and overall vigor, and comes to oppose the primary $a$ process more effectively. This growth of the $b$ process over trials is thought to be responsible for nonassociative habituation of the US. To account for the short-lived time course of response habituation, it is further assumed that the $b$ process declines rapidly in strength over time in the absence of the US.

The opponent-process model, like other models employing active mechanisms, has no trouble accounting for the complementary effects of US preexposure on excitatory and inhibitory conditioning. The growth of the $b$ process after repeated presentations of the US should minimize the affective impact of the $a$ process and should retard learning to a conditioned excitatory stimulus $(\mathrm{CS}+)$. Because a conditioned inhibitory stimulus (CS-) is assumed to become associated with the $b$ process, there would also be greater opportunity for inhibitory conditioning due to the strengthening of the $b$ process during US preexposure.

Nonassociative habituation accounts have been challenged with the advent of sophisticated associative accounts, such as the Rescorla-Wagner model (Rescorla \& Wagner, 1972; Wagner \& Rescorla, 1972), which have been developed to explain how contextual stimuli can participate in Pavlovian conditioning situations. Associative accounts hold the common assumption that the experimental context is conditionable in the same manner as a dis crete CS. According to the Rescorla-Wagner model, for example, a US-pretreated context can "block" discrete trial learning to a $\mathrm{CS}+$, while providing a more excitatory background in which to imbed a CS - . Alternatively, the conditioning context may act as a comparator for performance to discrete cues embedded in that context. Preexposure to the US might inflate the associative strength of the context, modulating later performance to the CSs (Gibbon \& Balsam, 1981; Miller \& Schachtman, 1985).
The strongest tests applicable to associative accounts revolve around the contextual cues that are purported to control US preexposure effects. For example, associative accounts predict that US preexposure should affect acquisition only when the contextual cues present during US preexposure are also present during later conditioning (e.g., Ayres, Bombace, Shurtleff, \& Vigorito, 1985; Tomie, 1976). If the contextual cues differ across phases, the relevant associative processes will not be activated and the later conditioning should be unaffected. This prediction encompasses the effects of US preexposure on both conditioned excitation and conditioned inhibition. Alternatively, nonassociative habituation accounts predict that, in principle, habituation-like effects should transfer readily across contexts. Note that the failure to observe situational control of a US preexposure effect, although suggestive, cannot be taken as definitive evidence of a nonassociative mechanism. It could be that the contextual cues of relevance to the animal have simply not been altered, or that the animal has learned that the US is unpredictable (see Baker \& Mercier, 1982; Baker, Mercier, Gabel, \& Baker, 1981).

Associative accounts are also in disagreement with nonassociative habituation accounts over the durability of US preexposure effects. This follows because of the assumption that the processes responsible for learning about the context are fundamentally the same as those controlling learning about discrete stimuli. Thus, an associatively based account that accepts the laws of Pavlovian conditioning requires that US preexposure effects are temporally stable across intersession intervals, inasmuch as most conditioned responses are easily retained that long. This contrasts markedly with the short-term effects predicted by nonassociative habituation accounts. Because nonassociative habituation accounts assume that continued repetition of the US is necessary for subjects to remain habituated to it, whether a rest period is given after US preexposure is of pivotal importance in determining the effect of US preexposure on later conditioning (see Thompson \& Spencer, 1966). If conditioning begins immediately after the last US preexposure trial, nonassociative habituation should be strong and should have marked effects on the emergence of conditioned responding. Conversely, a rest period should allow nonassociative habituation to dissipate completely, leaving later conditioning unaffected.

To complete our descriptions of available accounts, we should mention the dual-process accounts, which include a mixture of associative and nonassociative habituationlike mechanisms (e.g., Schull, 1979; Wagner \& Larew, 1985; Whitlow \& Wagner, 1984). These accounts bear a strong resemblance to their nonassociative-active counterparts; both suggest that US preexposure results in the growth of a secondary process. The major difference is that dual-process accounts assume that the secondary process can be activated conditionally by contextual cues present at the time of US preexposure. For example, Schull's conditioned-opponent theory includes an associa- 
tive cuing mechanism-the evocation of the secondary process by context-as well as nonassociative strengthening of the secondary process by repetition per se.

To date, the conditioning literature has contained many reports that are consistent with the explanation offered by the associative accounts. For example, Saladin and Tait (1986), using rabbits in a nictitating membrane conditioning paradigm, demonstrated that US preexposure can retard the emergence of excitatory conditioning while facilitating the development of inhibitory conditioning. Each of these US preexposure effects was specific to the particular target context in which the US preexposures were delivered and failed to occur when conditioning $o c-$ curred in another, nonpreexposed context. These data are but one example of many reports of context-specific US preexposure effects on discrete trial excitatory and inhibitory learning (e.g., Ayres et al., 1985; Hinson, 1982; Matzel, Brown, \& Miller, 1987; Randich \& Ross, 1985; Tomie, 1976). Other support for the claims of associative accounts include the observation that unreinforced exposure to a US-preexposed context in advance of conditioning (e.g., Baker \& Mercier, 1982; Hinson, 1982; Matzel et al., 1987; Randich, 1981; Tomie, 1976) is an effective means of reducing the interference effect on excitatory conditioning.

On the other hand, there are few convincing examples of a nonassociative habituation effect of US preexposure on the conditioning of discrete CSs (e.g., Randich, 1981). A few studies involving drug USs do appear to point to this type of mechanism (e.g., Domjan \& Best, 1980; Riley, Dacanay, \& Mastropaolo, 1984). It could be that a dearth of evidence for a nonassociative habituation effect is a result of the widespread use of US preexposure parameters that would not promote the development of short-term nonassociative habituation; in most preexposure studies (e.g., Saladin \& Tait, 1986), the USs were distributed across many sessions with few trials in each session and relatively long interstimulus intervals (ISIs). More important for the present purposes is that the effects of US preexposure on conditioning have almost always been assessed after a 24-h rest period. Given that most examples of response habituation are short-lasting, this rest period may have allowed nonassociative habituation effects, if they did initially develop, to dissipate, leaving only the more durable associative effects.

Domjan and Best (1980) have provided evidence that supports the contention that the rest interval between US preexposure and conditioning may have contributed to the many failures to find evidence of a nonassociative habituation effect. After a series of experiments (e.g., Best \& Domjan, 1979; Domjan, 1978; Domjan \& Best, 1977, 1980 ), they came to the conclusion that interference with excitatory taste-aversion learning after US preexposure might be based upon different mechanisms, depending upon whether the US pretreatment is administered shortly before or well in advance of conditioning. Specifically, the effects of preexposure to a lithium chloride US oc- curring a full 2-4 days in advance of conditioning were attenuated by changes in the method of drug injection and changes in visual and spatial cues. This result implied an associative mechanism. In contrast, groups receiving preconditioning experience with lithium chloride only $3 \mathrm{~h}$ before conditioning did not show any evidence of attenuation after either manipulation. This latter result is consistent with a nonassociative habituation mechanism, and indicates that whether a rest interval is included is a crucial variable.

The present experiment is an attempt to provide evidence of a short-term nonassociative habituation effect of US preexposures on conditioning to discrete CSs in the conditioned suppression paradigm with rats. The present study differs from previous conditioned suppression experiments in that we used US parameters that nonassociative habituation accounts would regard as conducive to the development of short-term habituation (see Solomon \& Corbit, 1974). A single session of US preexposures was used, which included 210 trials and relatively short, 120-sec ISIs. The subsequent conditioning phase either began immediately or was delayed by $24 \mathrm{~h}$. If short-term nonassociative habituation processes are involved, these processes should influence conditioning immediately, as they did in the Domjan and Best experiments, but should not survive intact the 24-h rest period in the home cage. We also used the traditional context-shift test of associativity to contrast associative and nonassociative accounts of US preexposure.

After a baseline rate of pressing a lever for food in a standard operant leverbox was established, four groups of experimental rats were given preexposure to a footshock US. The four experimental groups were distinguished by whether US preexposure and conditioning $\alpha$ curred in the same or a different context, and whether conditioning began immediately or after a 24 -h rest period in the home cage. For conditioning, we used an intermixed backward procedure involving two types of trials: one backward CS - followed shocks that were signaled by a forward CS + , and a second backward CS - followed shocks that were unsignaled. After conditioning, the rats were returned to the leverbox for testing. This included tests of ability of the concurrently established forward $\mathrm{CS}+$ to suppress the leverpress baseline, and more importantly, tests of the ability of the backward CS - s based upon signaled and unsignaled USs to inhibit suppression to a separately established test CS + (see Rescorla, 1969). Four independent control groups did not receive preexposures to the US. The rats of the control groups sat in the experimental apparatus during the preexposure phase in the absence of the US and other stimulus events. These four control groups were matched to the experimental groups with respect to the context and rest variables.

The signaling variable introduced during backward conditioning was included to distinguish among the various associative accounts (see Williams \& Overmier, 1988). 
Some associative accounts, the Rescorla-Wagner (1972) model in particular, suggest that contextual conditioning at the time of backward CS - presentation should be greater following a US-alone episode than following a CS-US episode in which the context can be overshadowed by the nominal CS. Accordingly, the Rescorla-Wagner model predicts that signaling the US should reduce the magnitude of backward inhibitory conditioning. Other associative accounts predict no effect of signaling, because they do not include the assumption that discrete CSs and the surrounding context compete for associative strength (e.g., Balsam \& Gibbon, 1988; Gibbon \& Balsam, 1981). Finally, dual-process accounts (e.g. Schull, 1979; Wagner \& Larew, 1985) hold that the added signal augments inhibitory conditioning by acting as an additional retrieval cue for a secondary process.

\section{METHOD}

\section{Subjects}

Forty-eight male albino rats, $350-450 \mathrm{~g}$ in weight and 90 days old on arrival, were obtained from Holtzman Co., Madison, WI. The rats were gradually reduced to $85 \%$ of their free-feoding weights for the experiment. They were housed individually with free access to water in a colony room that was continuously lit.

\section{Apparatus}

Three distinctive types of apparatuses were used. Each apparatus was enclosed within an insulated and sound-attenuated chest. There were four copies of each apparatus, allowing squads of 4 rats to be run concurrently. Leverpress training and stimulus testing occurred in a standard Coulbourn E10-10 leverbox. Each leverbox measured $29 \times 23 \times 28 \mathrm{~cm}$. The side walls were made of Plexiglas, and the ceiling, stimulus panel, and back wall were aluminum. The floor was constructed of 8-mm-diam stainless steel rods spaced $2 \mathrm{~cm}$ apart, center to center. General lighting was provided by a 4-W houselight mounted in the center of the ceiling. The houselight was normally illuminated during the entire session. A recessed food cup was located in the middle of the stimulus panel, $2 \mathrm{~cm}$ above the floor. A wall light, which consisted of six 4-W multicolored jeweled lamps arranged in 2 rows of three lamps, was located $4 \mathrm{~cm}$ directly above the food cup. Each leverbox was equipped with a response lever located $5 \mathrm{~cm}$ to the right of the food cup.

Two distinctively different boxes were used for the preexposure and conditioning phases in the context-switch groups. One box was constructed entirely of sealed wood and measured $27 \times 10 \times 24 \mathrm{~cm}$ (wooden box). The ceiling consisted of a removable, sliding wooden lid with ventilation holes. The floor was constructed of stainless steel rods, $8 \mathrm{~mm}$ in diameter, spaced $3 \mathrm{~cm}$ apart. A 4-W houselight was mounted in the center of one side wall $5 \mathrm{~cm}$ from the ceiling. The second box measured $27 \times 27 \times 12 \mathrm{~cm}$ (black box). It had a stimulus panel that was constructed of wood and painted flat black. The ceiling, side walls and back wall were made of Plexiglas. A 4-W houselight was mounted on the stimulus panel, $1 \mathrm{~cm}$ from the side wall, and midway between the floor and ceiling. The floor consisted of $1-\mathrm{mm}$ stainless steel bars spaced $1.5 \mathrm{~cm}$ apart. Backward conditioning always occurred in the wooden box. The US preexposure treatment, however, could occur in either the wooden or the black box.

All conditioned stimuli were $30 \mathrm{sec}$ in duration. The forward CS + used to signal shocks during backward conditioning was the flashing off and on $(1 \mathrm{~Hz})$ of the normally illuminated houselight in the wooden box. The backward CS $-\mathrm{s}$ were a tone $(1000 \mathrm{~Hz}, 84 \mathrm{~dB}$ SPL) and a click (10 Hz, $75 \mathrm{~dB}$ SPL), counterbalanced across sub- jects for assignment to signaled and unsignaled trials. Speakers for the click and tone were mounted on the inside wall of the soundattenuated chest. The flashing on and off $(1 \mathrm{~Hz})$ of the wall light (all six lamps flashing in unison) in the leverbox was used as the test CS + on summation trials. The US was a $1-\mathrm{sec}, 0.5-\mathrm{mA}$ footshock applied to the grid floor by a Grason Stadler shock generator and scrambler (Model E1064GS). Stimulus parameters were the same for the three apparatuses.

Background white noise (69 dB SPL) was presented continuously in the experimental room. A PDP-8A computer with SUPER-SKED software controlled the timing of stimulus events and recorded leverpresses.

\section{Procedure}

Pretraining. All rats were given preliminary training to press the lever for food. The rats first received 1 day of magazine training in which 60 reinforcers (45-mg food pellets, Bioserv Formula 21) were randomly delivered on a 40 -sec variable-time schedule. On the following day, each rat was trained to press the lever for a food pellet, with each response reinforced. A variable-interval (VI) 10-sec schedule was introduced at the start of the next day. The VI value was progressively increased to $60 \mathrm{sec}$ within that session. The rats were then given 5 more days of VI 60 -sec training. All VI sessions lasted $60 \mathrm{~min}$.

Preexposure. The rats differed with respect to their treatment during the preexposure phase. The preexposure phase involved a $2 \times 2$ factorial design. The factors included whether rats were USpreexposed (Px) or nonpreexposed (NPx), and whether these treatments occurred in the same box as the later conditioning (Same) or in a different box (Diff). Accordingly, the $2 \times 2$ design included four independent conditions $(n=12): \mathrm{Px} / \mathrm{Same}, \mathrm{Px} / \mathrm{Diff}$, $\mathrm{NPx} / \mathrm{Same}$, and NPx/Diff. The rats in the Px conditions received a single session of preexposure to unsignaled shocks. There were 210 shocks, presented $120 \mathrm{sec}$ apart on average (range $90-180 \mathrm{sec}$ ). The rats in the NPx conditions were placed in the experimental environment for the same amount of time as the Px subjects but received no stimulus events. For the Same conditions, the preexposure treatment was administered in the same box as was used for conditioning (wooden box). For the Diff conditions, preexposure occurred in a different box than the one used for conditioning (black box).

Rest. Following the US preexposure phase, each of the preexposure conditions was split into two groups. The groups received different duration rest intervals between preexposure and conditioning. For the rest (R) group, the rest period was a full $24 \mathrm{~h}$. The no-rest (NR) group received conditioning immediately after preexposure. The rats in the $\mathbf{R}$ group were removed following the last preexposure trial and were returned to their home cages, where they remained until the next day. Immediately after the last US preexposure trial, the rats in the NR group were removed from the preexposure box and were brought back to their home cages, where they remained for about $10 \mathrm{sec}$. They were then transported back to the experimental room and placed in the conditioning box. The entire process took approximately $3 \mathrm{~min}$. Thus, the R and NR groups were equated for amount of handling by the experimenter between the preexposure and conditioning phases, and differed only in the amount of time in the home cage.

With the rest factor included, there were three between-subjects factors; two factors were manipulated in the preexposure phase ( $P_{x}$ vs. NPx, Same vs. Diff) and one factor was manipulated in the rest phase ( $R$ vs. NR). These eight groups were composed of 6 rats each. All groups were treated similarly after the rest phase.

Conditioning. Excitatory and inhibitory conditioning treatments were administered in the wooden conditioning box. The rats in all groups received intermixed conditioning of two backward CS $-\mathrm{s}$; one backward CS - followed shocks that were signaled by a forward CS + (Sig); the other backward CS - followed unsignaled 
shocks (Unsig). The forward CS + was the flashing off and on ( $1 \mathrm{~Hz}$ ) of the normally illuminated houselight, lasting $30 \mathrm{sec}$. This visual CS + terminated with the onset of shock. The backward CS $-\mathrm{s}$ were the auditory tone and the click; both were $30 \mathrm{sec}$ in duration. The auditory stimuli were counterbalanced across subjects for assignment to signaled and unsignaled trials. Onset of each CS - was coincident with shock offset. The rats received one session of conditioning comprising 116 trials. There were 58 signaled and 58 unsignaled trials presented in random order, with a mean interval between shocks of $120 \mathrm{sec}$ (range $90-180 \mathrm{sec}$ ).

Backward CS - and forward CS + tests. On the next day, a new test CS + was first established for the summation test. This conditioning occurred off the baseline in the leverbox with the response manipulandum removed. The manipulandum hole and the food cup were covered by aluminum panels. The test CS + was the flashing wall light lasting $30 \mathrm{sec}$. Shock onset occurred at test $\mathrm{CS}+$ termination. Seven sessions of conditioning were given to the test CS + . There were eight reinforced trials per session, with a mean interval between shocks of $350 \mathrm{sec}$ (range 270-430 sec).

The ability of the two auditory backward $\mathrm{CS}-\mathrm{s}$ to inhibit suppression to this new test $\mathrm{CS}+$ was then assessed in a summation test. Eight unreinforced presentations of the 30 -sec stimuli were superimposed on the VI 60 -sec leverpress baseline. There were four types of trials: (1) the test CS + alone, (2) the test CS + in simultaneous compound with the backward CS - based upon the unsignaled US, (3) the test CS + in simultaneous compound with the backward CS - based upon the signaled US, and (4) suppression testing of the forward $\mathrm{CS}+$, which involved the flashing of the normally illuminated houselight $(1 \mathrm{~Hz})$. We have observed substantial stimulus generalization between the flashing houselights of the wooden conditioning box and of the leverbox, presumably because they both leave the surrounding chamber in complete darkness for brief periods of time. This allowed us to use suppression during the flashing houselight of the leverbox as an index of the magnitude of conditioning in response to the flashing houselight in the wooden box. Each trial type was presented twice in the session. Trials were blockrandomized. Within blocks of four trials, each trial type occurred once in random order. The session lasted $1 \mathrm{~h}, 57 \mathrm{~min}$, with trials separated by an average of $17 \mathrm{~min}$. Reinforcers could be delivered during a trial.

\section{Data Analysis}

Daily suppression ratios were calculated for each of the trial types of the backward CS - and forward CS + tests. This suppression ratio took the form $d u r /(d u r+p r e)$, where $d u r$ is the total number of responses made during the two 30-sec test trials and pre is the total number of responses made in the two $30-\mathrm{sec}$ intervals just prior to the test trials. The data were subjected to analysis of variance (ANOVA) with a rejection criterion of $p=.05$.

\section{RESULTS}

\section{Forward CS+ Test}

The results of the suppression test of the forward CS+ that was established during backward conditioning are presented in Figure 1. The figure shows the mean suppression in response to the forward CS+ as a function of the preexposure, context, and rest variables. As expected, the US preexposure treatment did have large interference effects on excitatory conditioning to the forward CS + . These effects, however, were confined to the $\mathrm{Px} /$ Same groups. This is shown in Figure 1 by the much reduced suppression in response to the forward CS + in the $\mathrm{Px} / \mathrm{Same}$ condition. Within this condition, no differences emerged between the R and NR groups. Thus, the

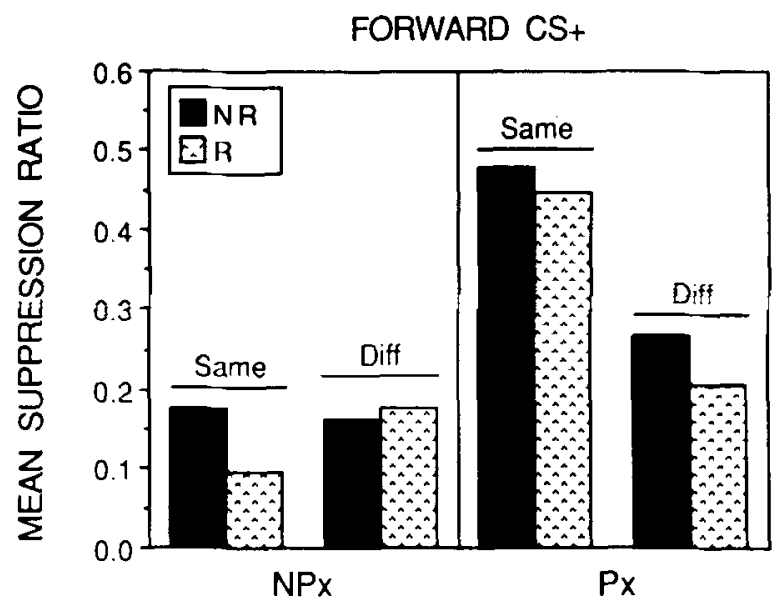

Figure 1. Mean suppression ratios in response to the forward CS+ used during the beckward conditioning phase. $P x=U S$ preexposed, NPx $=$ nonpreexposed, Same $=$ conditioning occurred in the same context as the preexposure treatment, Diff = conditioning occurred in a different context then the preexposure treatment, $N R=$ no rest, conditioning began immediately after the last preexpasure trial, $R$ $=$ rest, conditioning occurred after a $24 \mathrm{~h}$ rest period in the home cage.

data revealed an effect of context as predicted by associative accounts, but did not reveal an effect of rest as predicted by nonassociative habituation accounts.

Statistical analyses supported these conclusions. An ANOVA $(2 \times 2 \times 2)$ was conducted that included the between-subjects variables of preexposure (NPx vs. Px), context (Same vs. Diff), and rest ( $R$ vs. NR). The ANOVA yielded a significant preexposure $\times$ context interaction $[F(1,40)=10.16]$, which resulted from less suppression in the $\mathrm{Px} / \mathrm{Same}$ condition than in the Px/Diff $[t(40)=2.93], \mathrm{NPx} /$ Same $[t(40)=3.49]$, and NPx/Diff $[t(40)=3.22]$ conditions. No other significant differences were found.

\section{Backward CS - Tests}

The results of primary interest are the degree to which the backward $\mathrm{CS}-\mathrm{s}$ based upon signaled and unsignaled USs were able to inhibit suppression by the test CS+. Mean suppression evoked by the test $\mathrm{CS}+$ was moderate. There appeared to be generally less suppression to the test CS + in the Px condition (.214) than in the NPx condition (.168). A preliminary $2 \times 2 \times 2$ ANOVA applied to the suppression ratios on test CS + trials, however, did not uncover any reliable main effects or interactions. Because our primary interest was the change in suppression in response to the test CS + on compound trials involving either signaled or unsignaled backward $\mathrm{CS}-\mathrm{s}$, we calculated a change score that reflects the net effect of the added CS - on compound trials (test CS + alone - compound). On this measure, conditioned inhibition is indicated by negative change scores-that is, reduced suppression on compound trials relative to test $\mathrm{CS}+$-alone trials. The original suppression ratios and the resulting change scores are contained in Table 1. 
Table 1

Mean Suppression Ratios and Mean Change Scores in the Summation Test

\begin{tabular}{lccccrc}
\hline & \multicolumn{3}{c}{ Suppression Ratio } & & \multicolumn{2}{c}{ Change Score } \\
\cline { 2 - 3 } \multicolumn{1}{c}{ Group } & Test CS + & Unsig & Sig & & Unsig & Sig \\
\hline NPx/Same/NR & .146 & .113 & .101 & .033 & .045 \\
NPx/Same/R & .176 & .138 & .169 & .038 & .007 \\
NPx/Diff/NR & .205 & .226 & .141 & -.021 & .064 \\
NPx/Diff/R & .144 & .101 & .127 & .043 & .017 \\
Px/Same/NR & .178 & .371 & .337 & -.193 & -.159 \\
Px/Same/R & .167 & .251 & .217 & -.084 & -.050 \\
Px/Diff/NR & .244 & .193 & .176 & .051 & .068 \\
Px/Diff/R & .266 & .194 & .221 & .072 & .045 \\
\hline
\end{tabular}

Note-Unsig = unsignaled US, Sig $=$ signaled US, NPx = nonpreexposed, $\mathbf{P x}=$ US preexposed, Same = conditioning occurred in the same context as the preexposure treatment, Diff = conditioning occurred in a different context than the preexposure treatment, $N R=$ no rest, conditioning began immediately after the last preexposure trial, $\mathbf{R}=$ rest, conditioning began $24 \mathrm{~h}$ after the last preexposure trial.

Figure 2 shows the mean change in suppression ratios produced by the added CS - on summation trials. An inspection of the figure shows that the single session of conditioning was not effective in establishing either the signaled or the unsignaled backward $\mathrm{CS}-\mathrm{s}$ as conditioned inhibitors. This is indicated by change scores that were not negatively signed in the NPx condition. If anything, the change scores were slightly positive in most cases. Thus, the backward conditioning was not sufficient in itself to produce inhibitory learning.

In contrast to the NPx condition, there was evidence of robust conditioned inhibition in the Px condition. Whether or not conditioned inhibition was obtained depended both on the context in which US preexposures oc- curred and on whether rats rested in the interval between the last US preexposure trial and the first conditioning trial. Specifically, negative change scores different from zero were observed only in the $\mathbf{P x} /$ Same groups. This facilitative effect of US preexposure on inhibitory conditioning was attenuated by the $24-\mathrm{h}$ rest interval. There was no effect of the signaling variable.

To confirm these interpretations, a $2 \times 2 \times 2 \times 2$ mixed model ANOVA was applied to the change scores. This analysis included the between-subjects factors of preexposure, context, and rest. The within-subjects factor was the backward CS - (Unsig vs. Sig). The ANOVA yielded significant effects for preexposure $[F(1,40)=$ 9.71] and context $[F(1,40)=14.28]$, and an interaction of preexposure $\times$ context $[F(1,40)=15.50]$. There were no statistically reliable main effects or interactions involving the backward CS - or rest variables. Of particular interest is the preexposure $X$ context interaction, which confirmed the major prediction of associative accounts that the effects of US preexposure on backward conditioned inhibition should be context-specific. Follow-up contrasts showed that the interaction was due to negatively signed scores which were different from zero in the Px/Same condition $[t(40)=3.66]$. Moreover, the Px/Same condition differed reliably from the Px/Diff condition $[t(40)=$ 5.47], and from the two nonpreexposed conditions $[\mathrm{NPx} / \mathrm{Same}, t(40)=4.69$, and NPx/Diff, $t(40)=4.21]$.

Although the omnibus ANOVA did not reveal main effects or interactions involving the rest variable, we felt justified in conducting additional contrasts involving the rest variable given the a priori nature of the predictions derived from nonassociative habituation accounts. These

BACKWARD CS-S

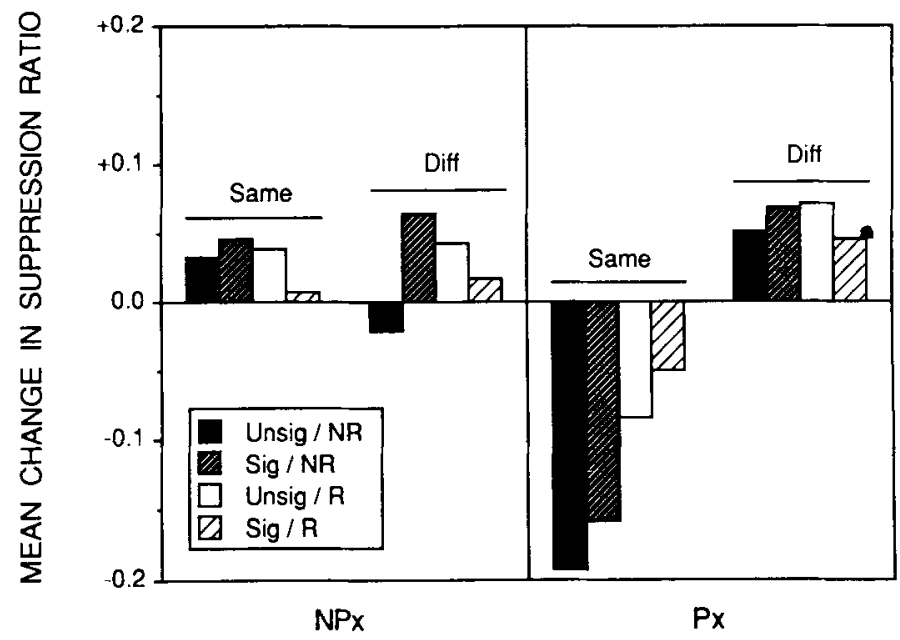

Figure 2. Mean change in suppression ratios (test CS + alone - summation trial) produced by the added backward CS - on compound trials of the summation test. Px $=$ US preexposed, NPx = nonpreexposed, Unsig $=$ backward CS - based on an unsignaled US, Sig = backward CS - based on a forward CS +-signaled US, Same = conditioning occurred in the same context as the preexposure treatment, Dif = conditioning occurred in a different context than the preexposure treatment, $\mathbf{N R}=$ no rest, conditioning began immediately after the last preexposure trial, $\mathbf{R}=$ rest, conditioning occurred after a $24 \mathrm{~h}$ rest period in the home cage. 
contrasts were applied to the Px/Same and Px/Diff groups in which rest effects would be anticipated by a nonassociative account. Although no differences were detected in the $\mathrm{Px} / \mathrm{Diff}$ condition, in the Px/Same condition, the change scores for the two backward CS - s taken together were significantly more negative in the NR group than in the $\mathrm{R}$ group $[\mathrm{Px} / \mathrm{Same} / \mathrm{NR}=-.176$ vs. $\mathrm{Px} / \mathrm{Same} / \mathrm{R}$ $=-.067, t(40)=2.27$ ]. In addition, backward inhibitory conditioning as shown by negative change scores different from zero occurred only when rats given US preexposure in the same context had no rest [Group $\mathrm{Px} /$ Same/NR, $t(40)=3.71$ ], not after $24 \mathrm{~h}$ of home cage rest [Group Px/Same/R, $t(40)=1.44]$. Finally, Group $\mathrm{Px} /$ Same/R differed reliably from Group Px/Diff/R $[t(40)$ $=2.63$ ], indicating that even in the rest groups, US preexposure in the same context had a facilitative effect on backward inhibitory conditioning.

\section{DISCUSSION}

Despite experimental conditions that would emphasize the role of short-term nonassociative habituation, we found no evidence that a nonassociative habituation mechanism was responsible for the interference of excitatory conditioning after US preexposure. Our current parameters yielded a substantial US preexposure interference effect to the forward CS + , which occurred only when conditioning was administered in the same context as had been used for the US preexposure. Thus, contrary to the predictions of nonassociative habituation accounts, the effect of US preexposure on excitatory conditioning did not transfer across contexts. This finding, however, is consistent with associative accounts. Associative accounts require context specificity because they attribute US preexposure effects to associations acquired between contextual cues and the US in the preexposure phase. Our data further indicate that the interference effect on excitatory conditioning was unchanged in magnitude after the 24-h rest interval. There was no evidence of a short-term nonassociative habituation effect. Together, the context specificity and durability of the interference effect on excitatory conditioning strongly implicate an associative mechanism.

There was some evidence pointing to a nonassociative habituation effect in the case of inhibitory conditioning. The nonassociative-active models (e.g., Solomon \& Corbit, 1974) correctly predicted that US preexposure would facilitate inhibitory conditioning. More importantly, the 24-h rest period in the home cage after US preexposure reduced the magnitude of, but did not completely abolish, the US preexposure effect on backward conditioned inhibition. This latter observation is uniquely predicted by nonassociative habituation accounts, which regard US preexposure effects as temporary reductions in US efficacy.

As for the failure to find an effect of US preexposure on inhibitory conditioning in the different-context group
(Group PX/Diff/NR), a nonassociative habituation account might assume that handling the rats during the brief period between the last US preexposure trial and the first conditioning trial acted as a distractor and caused dishabituation (Pavlov, 1927). It is well documented that the magnitude of an unconditioned response to a preexposed US can be reinstated to original levels upon presentation of a distracting stimulus in the ISI (e.g., Harris, 1943; Terry, 1976; Thompson \& Spencer, 1966; Whitlow, 1975; Whitlow \& Wagner, 1984). To produce different levels of dishabituation in Groups Px/Same/NR and Px/Diff/NR, nonassociative habituation accounts would assume that returning rats to a preexposed context would produce less dishabituation than would be produced by placing them into a novel context. This latter assumption is not unreasonable given that the degree of dishabituation obtained appears to be partially determined by the novelty of the distracting stimulus (see Bindra, 1959; Thompson \& Spencer, 1966). Thus, nonassociative habituation accounts can explain the difference in the degree of inhibitory conditioning between Groups Px/Same/NR and Px/Same/R, and between Groups Px/Same/NR and Px/Diff/NR.

What the nonassociative habituation accounts fail to explain is the occurrence of a durable US preexposure effect on backward inhibitory conditioning in Group $\mathrm{Px} / \mathrm{Same} / \mathrm{R}$. A 24-h rest period in the home cage surely would have provided ample opportunity for novelty and dishabituation. The additional change in context between the US preexposure and the conditioning phases would have provided little extra opportunity for dishabituation above that already provided by the rest interval alone. Accordingly, there would be no reason to expect that a durable US preexposure effect on inhibitory conditioning would be eliminated by a change in context. This is powerful evidence against a short-term nonassociative habituation account. We should note that the occurrence of a durable US preexposure effect, taken by itself, does not argue against nonassociative mechanisms in general. It argues against only nonassociative accounts based upon short-term habituation such as the opponent-process model (e.g., Solomon \& Corbit, 1974). Other nonassociative accounts that might allow for longer lasting effects, however, are contradicted by the context specificity of our durable US preexposure effect.

In summary, although nonassociative habituation accounts do gain a small measure of support from our backward CS - data, we believe that associative accounts provide a more inclusive account of the results of the present experiment. The persistence of the effects of US preexposure for at least $24 \mathrm{~h}$, which included effects on both excitatory and inhibitory conditioning, points toward an associative mechanism. It is unclear how nonassociative habituation accounts, such as the opponent-process model, could account for the existence of such long-lasting effects which were context-specific. Finally, with respect to the attenuation of inhibitory conditioning after the 24-h rest interval (Group Px/Same/R vs. Group 
$\mathrm{Px} / \mathrm{Same} / \mathrm{NR}$ ), one might argue that this effect could also be explained by an associative account that allows for a rapid degree of forgetting.

Although one could envision a purely associative interpretation that fully accounts for our data, we find the dual-process accounts more persuasive. First, there is no evidence that rapid forgetting occurs over $24 \mathrm{~h}$ in a conditioned suppression paradigm (e.g., Campbell \& Campbell, 1962; Gleitman \& Holmes, 1967; Hendersen, 1978). Even with rapid forgetting, a purely associative account would also have to explain why the forgetting of context excitation would have a large asymmetric effect on the backward $\mathrm{CS}-\mathrm{s}$, but would have no complementary effect on the forward CS +. Accordingly, our results are more comfortably accommodated by an account which is predominantly associative, but which contains a small nonassociative, habituation-like component (e.g., Schull, 1979; Wagner \& Larew, 1985).

Finally, some comment should be made on the signaling manipulation introduced during backward conditioning, which had no impact on the degree of conditioned inhibition expressed in the latter summation test. Our failure to observe an effect of signaling is consistent with the idea that the formation of the signal-US association does not influence learning about the context (e.g., Balsam \& Gibbon, 1988). However, this conclusion is not as penetrating as it may first appear. One could easily argue that the amount of suppression observed on the forward CS + test reflects asymptotic levels of conditioning on the last few trials of conditioning. Thus it could be maintained that, for the most part, the forward CS + was not highly excitatory during the conditioning phase. If so, the signaling variable would have had little overall impact. This argument is especially plausible in the Px/Same condition, in which the forward CS + did not suppress the leverpress baseline. Unfortunately, our experimental procedures precluded collection of trial-by-trial behavioral indexes of the suppressive properties of the forward CS+ during backward conditioning. This makes it difficult to evaluate the claim that the forward CS + was a weak CS+ over the majority of the conditioning phase.

\section{REFERENCES}

Ayres, J. J. B., Bombace, J. C., Shurtleff, D., \& Vigorito, M. (1985). Conditioned suppression tests of the context-blocking hypothesis: Testing in the absence of the preconditioned context. Joumal of Experimental Psychology: Animal Behavior Processes, 11, 1-14.

Baker, A. G., Mercier, P. (1982). Manipulation of the apparatus and response context may reduce the US pre-exposure interference effect. Quarterly Journal of Experimental Psychology, 34B, 221-234.

Baker, A. G., Mercier, P., Gabel, J., \& Baker, P. A. (1981). Contextual conditioning and the US preexposure effect in conditioned fear. Journal of Experimental Psychology: Animal Behavior Processes, 7, 109-128.

Balsam, P. D., \& Gibbon, J. (1988). Formation of tone-US associations does not interfere with the formation of context-US associations in pigeons. Joumal of Experimental Psychology: Animal Behavior Processes, 14, 401-412.
Best, M. R., Domjan, M. (1979). Characteristics of the lithiummediated proximal US-preexposure effect in flavor-aversion conditioning. Animal Learning \& Behavior, 7, 433-440.

BindRA, D. (1959). Stimulus change, reactions to novelty, and response decrement. Psychological Review, 66, 96-103.

Campeell, B. A., \& CAMpaell, E. H. (1962). Retention and extinction of learned fear in infant and adult rats. Journal of Comparative \& Physiological Psychology, 55, 1-8.

DENNY, M. R. (1971). Relaxation theory and experiments. In F. R. Brush (Ed.), Aversive conditioning and learning (pp. 235-295). New York: Academic Press.

Domian, M. (1978). Effects of proximal unconditioned stimulus preexposure on ingestional aversions learned as a result of taste presentation following drug treatment. Animal Learning \& Behavior, 6, 133-142.

Domjan, M., \& Best, M. R. (1977). Paradoxical effects of proximal unconditioned stimulus preexposure: Interference with and conditioning of a taste aversion. Journal of Experimental Psychology: Animal Behavior Processes, 3, 310-321.

DOMuA, M., \& BEST, M. R. (1980). Interference with ingestional aversion learning produced by preexposure to the unconditioned stimulus: Associative and nonassociative aspects. Learning \& Motivation, 11, 522-537.

Gibbon, J., \& Balsam, P. D. (1981). Spreading association in time. In C. M. Locurto, H. S. Terrace, \& J. Gibbon (Eds.), Autoshaping and conditioning theory (pp. 219-253). New York: Academic Press.

Gleitman, H., \& Holmes, P. A. (1967). Retention of incompletely learned CER in rats. Psychonomic Science, 7, 19-20.

HARRIS, J. D. (1943). Habituatory response decrement in the intact organism. Psychological Bulletin, 40, 385-422.

HENDERSEN, R. W. (1978). Forgetting of conditioned fear inhibition. Learning \& Motivation, 9, 16-30.

HINSON, R. E. (1982). Effects of UCS preexposure on excitatory and inhibitory rabbit eyelid conditioning: An associative effect of conditioned contextual stimuli. Joumal of Experimental Psychology: Animal Behavior Processes, 8, 49-61.

JenNings, H. S. (1906). Behavior of lower organisms. New York: Columbia University Press.

KAMIN, L. J. (1961). Apparent adaptation effects in the acquisition of a conditioned emotional response. Canadian Journal of Psychology, 15, 176-188.

LOLORDO, V. M., \& RANDICH, A. (1981). Effects of experience of electric shock upon subsequent conditioning of an emotional response: Associative and non-associative accounts. In P. Harzem \& M. D. Zeiler (Eds.), Advances in analysis of behavior: Vol. 2. Predictabil. ity, correlation, and contiguity (pp. 247-285). New York: Wiley.

MaCDonald, A. (1946). The effect of adaptation to the unconditioned stimulus upon the formation of conditioned avoidance responses. Journal of Experimental Psychology, 36, 1-12.

Matzel, L. D., Brown, A. M., Miller, R. R. (1987). Associative effects of US preexposure: Modulation of conditioned responding by an excitatory training context. Journal of Experimental Psychology: Animal Behavior Processes, 13, 65-72.

Miller, R. R., \& Schachtman, T. R. (1985). Conditioning context as an associative baseline: Implications for response generation and the nature of conditioned inhibition. In R. R. Miller \& N. E. Spear (Eds.), Information processing in animals: Conditioned inhibition (pp. 51-88). Hillsdale, NJ: Erlbaum.

MIs, F. W., \& MoORE, J. W. (1973). Effect of preacquisition UCS exposure on classical conditioning of the rabbit's nictitating membrane response. Learning \& Motivation, 4, 108-114.

Overmier, J. B., Payne, R. J., Brackbill, R. M., Linder, B., \& LAWRY, J. A. (1979). On the mechanism of the post-asymptotic CR decrement phenomenon. Acta Neurobiologiae Experimentalis, 39, 603-620.

Pavlov, I. P. (1927). Conditioned reflexes. London: Clarendon Press. Prosser, C. L., \& Hunter, W. S. (1936). The extinction of the startle responses and spinal reflexes in the white rat. American Journal of Physiology, 117, 609-618. 
Randich A. (1981). The US preexposure phenomenon in the conditioned suppression paradigm: A role for conditioned situational stimuli. Learning \& Motivation, 12, 321-341.

RANDich, A., \& LoLoRDo, V. M. (1979a). Associative and nonassociative theories of the UCS preexposure phenomenon: Implications for Pavlovian conditioning. Psychological Bulletin, 86, 523-548.

RANDICH, A., LoLoRdo, V. M. (1979b). Preconditioning exposure to the unconditioned stimulus affects the acquisition of a conditioned emotional response. Learning \& Motivation, 10, 245-277.

Randich, A., \& Ross, R. T. (1985). Contextual stimuli mediate the effects of pre- and postexposure to the unconditioned stimulus on conditioned suppression. In P. D. Balsam \& A. Tomie (Eds.), Context and learning (pp. 105-132). Hillsdale, NJ: Erlbaum.

Rescorla, R. A. (1969). Pavlovian conditioned inhibition. Psychological Bulletin, 72, 77-94.

Rescorla, R. A., W Waner, A. R. (1972). A theory of Pavlovian conditioning: Variations in the effectiveness of reinforcement and nonreinforcement. In A. H. Black \& W. F. Prokasy (Eds.), Classical conditioning: Vol. 2. Current theory and research (pp. 64-99). New York: Appleton-Century-Crofts.

Riley, A. L., Dacanay, R. J., Mastropaolo, J. P. (1984). The effect of morphine preexposure on the acquisition of morphine-induced taste aversions: A nonassociative effect. Animal Learning \& Behavior, $12,157-162$.

SAlAdiN, M. E., \& TAIT, R. W. (1986). US preexposures retard excitatory and facilitate inhibitory conditioning of the rabbit's nictitating membrane response. Animal Learning \& Behavior, 14, 121-132.

SCHULL, J. (1979). A conditioned opponent theory of Pavlovian conditioning and habituation. Psychology of Leaming \& Motivation, 13, $57-90$.

Solomon, R. L., \& CoRBiT, J. D. (1974). An opponent-process theory of motivation: 1. Temporal dynamics of affect. Psychological Review, 81, 119-145.

TAYLOR, J. A. (1956). Level of conditioning and intensity of the adaptation stimulus. Journal of Experimental Psychology, 51, 127-130.
TERRY, W. S. (1976). Effects of priming unconditioned stimulus representation in short-term memory on Pavlovian conditioning. Journal of Experimental Psychology: Animal Behavior Processes, 2, 354-369.

Thompson, R. F., \& SPEncer, W. A. (1966). Habituation: A model phenomenon for the study of neural substrates of behavior. Psycho logical Review, 73, 16-43.

Tomie, A. (1976). Interference with autoshaping by prior context conditioning. Journal of Experimental Psychology: Animal Behavior Processes, 2, 323-334.

Wagner, A. R., LAREW, M. B. (1985). Opponent processes and Pavlovian inhibition. In R. R. Miller \& N. E. Spear (Eds.), Information processing in animals: Conditioned inhibition (pp. 233-265). Hillsdale, NJ: Erlbaum.

W Agner, A. R., Rescorla, R. A. (1972). Inhibition in Pavlovian conditioning: Application of a theory. In R. A. Boakes \& M. S. Halliday (Eds.), Inhibition and learning (pp. 301-336). London: Academic Press.

WENDT, G. R. (1931). Negative adaptation as an active positive antagonism. Psychological Bulletin, 28, 681-682.

WhItLow, J, W. (1975). Short-term memory in habituation and dishabituation. Joumal of Experimental Psychology: Animal Behavior Processes, 1, 189-206.

Whitlow, J. W., \& Wagner, A. R. (1984). Memory and habituation. In H. V. S. Peeke \& L. Petrinovich (Eds.), Habituation, sensitization, and behavior (pp. 103-153). Orlando, FL: Academic Press.

WILLIAMS, D. A., \& Overmier, J. B. (1988). Backward inhibitory conditioning with signaled and unsignaled unconditioned stimuli: Distribution of trials and intertrial interval. Jourmal of Experimental Psychology: Animal Behavior Processes, 14, 26-35.

(Manuscript received September 27, 1988; revision accepted for publication May 8,1989 .) 